\title{
Spiritually motivated restrictions on animal products have a limited impact on consumption of healthy plant-based foods
}

\author{
Hilary J. Bethancourt ${ }^{1,2 *}$, Mario Kratz ${ }^{3,4,5}$ and Kathleen O'Connor ${ }^{6}$ \\ ${ }^{1}$ Department of Biobehavioral Health, Pennsylvania State University, State College, PA, USA \\ ${ }^{2}$ Center for Studies in Demography and Ecology, University of Washington, Seattle, WA, USA \\ ${ }^{3}$ Division of Public Health Sciences, Fred Hutchinson Cancer Research Center, Seattle, WA, USA \\ ${ }^{4}$ Department of Epidemiology, School of Public Health, University of Washington, Seattle, WA, USA \\ ${ }^{5}$ Division of Metabolism, Endocrinology, and Nutrition, Department of Medicine, University of Washington, Seattle, WA, USA \\ ${ }^{6}$ Department of Anthropology, University of Washington, Seattle, WA, USA
}

(Submitted 12 January 2019 - Final revision received 11 June 2019 - Accepted 18 June 2019)

\section{Abstract}

Plant-based diets are considered healthier than many omnivorous diets. However, it is unclear that restriction of animal products necessarily motivates increased consumption of nutrient- and fibre-rich plant-based foods as opposed to energy-dense but nutrient-poor plant-based foods containing refined grains and added sugars and fats. The present study examined FFQ and food record data from ninety-nine individuals in the USA with varying degrees of adherence to the Orthodox Christian tradition of restricting meat, dairy and egg (MDE) products for $48 \mathrm{~d}$ prior to Easter to investigate whether restricting MDE products in the absence of explicit nutritional guidance would lead to increased consumption of healthy plant-based foods and greater likelihood of meeting dietary recommendations. Multiple linear regression models assessed changes in major food groups, energy and nutrients in relation to the degree of reduction in MDE consumption. Logistic regression analyses tested the odds of meeting 2015-2020 Dietary Guidelines for Americans on plant-based foods in relation to MDE restriction. Each serving reduction in MDE products was associated with small (approximately $0 \cdot 1-0 \cdot 7$ serving) increases in legumes, soya products and nuts/seeds (all $P$ values $<0 \cdot 005$ ). MDE restriction was not associated with higher odds of meeting recommendations on vegetable, fruit or whole-grain intake. Consumption of refined grains and added sugars did not change in relation to MDE restriction but remained above recommended thresholds, on average. These findings demonstrate that a reduction of MDE products for spiritual purposes may result in increases in some nutrient-rich plant-based foods but may not uniformly lead to a healthier dietary composition.

Key words: Plant-based diets: Vegetarian diets: Dietary recommendations: Orthodox Christians: Lent

Diets low in or free of animal products tend to be praised for containing less energy and saturated fat and abundant 'healthy', nutrient-dense, high- fibre plant-based foods, such as whole fruits and vegetables, whole grains, legumes, and nuts and seeds ${ }^{(1-3)}$. However, just as there is no single 'omnivorous' diet, the dietary composition of broadly defined 'plant-based' diets is not uniform within or across populations and may differ in relation to distinct motivations for removing animal products from the diet (i.e. health, ethical or religious reasons), length of adherence to a plant-based diet, food access, and the local food and culinary environment ${ }^{(3-5)}$. Vegetarian and vegan Seventh Day Adventists in the USA and Canada, for example, appear to consume more fruits and vegetables than non-Seventh Day Adventist vegetarians and vegans in the $\mathrm{UK}^{(6)}$. The vegetarian diets of South Asians also vary from those of American vegetarians in their relative amounts of vegetables, whole grains, nuts, desserts and fried foods ${ }^{(7)}$. Variation in the proportion of 'healthy' and 'unhealthy' plantbased foods in vegetarian and vegan diets may help explain varying susceptibility among vegetarians and vegans to weight gain ${ }^{(8)}$, overweight and obesity ${ }^{(7,9,10)}$, the metabolic syndrome ${ }^{(11,12)}$, diabetes $^{(10,13,14)}$, hypertension ${ }^{(10,15)}$, dyslipidaemia ${ }^{(10)}$, or cardiovascular-related mortality ${ }^{(16-20)}$.

In the USA, the growing market of vegetarian and vegan packaged products and fast-foods has also made it easier than ever before to transition from an omnivorous 'standard American' or industrialised diet ${ }^{(21)}$ to a 'plant-based' diet that is neither less energetically dense nor more fibre and nutrient rich $^{(22-24)}$. Thus, while the variability of meatless sources of

Abbreviations: FR, food record; cup-eq, cup equivalent; MDE, meat, dairy and egg; MET, metabolic equivalent value; OC, Orthodox Christian; Oz-eq, ounce equivalent.

* Corresponding author: Hilary J. Bethancourt, email hilaryjb@psu.edu 
protein, fat and micronutrients now facilitates a nutritionally adequate plant-based diet if pursued with care ${ }^{(2,25)}$, such diets may not necessarily be considerably healthier than omnivorous ones if they include the same or even greater amounts of added sugars, refined grains and other highly processed foods that are thought to contribute to weight gain and cardiometabolic disease risk among omnivorous populations ${ }^{(22-24,26-28)}$. It is not clear that restriction of animal products from the diet will necessarily result in higher consumption of whole grains, legumes, and fruits and vegetables among individuals who are not already accustomed to consuming such foods or who refrain from animal product consumption for reasons other than to improve health (e.g. ethical or religious reasons). Apart from the studies on North American Seventh Day Adventists, few studies have examined the extent to which North Americans restricting or omitting animal products, particularly when doing so for reasons other than health improvement, consume more healthy plant-based foods and fewer processed plant-based foods than their omnivorous counterparts.

The present study, therefore, explored the dietary and nutritional shifts of Orthodox Christians in the USA, who are encouraged as part of their spiritual practice to periodically 'fast' (abstain) from meat, dairy and egg (MDE) products as a spiritual discipline for the $48 \mathrm{~d}$ leading up to their 'Paschal' (Easter) celebration. This particular form of 'fasting' has been part of the Orthodox Christian (OC) tradition for over a millennium. While the resulting Lenten diet is different than other typical forms of vegetarian or vegan diets because it allows the consumption of shellfish and may also include restriction of olive oil on some days, this kind of MDE fasting results in the temporary adoption of a mostly plant-based diet. These periods of MDE fasting have been associated with potentially healthful shifts in nutritional composition among Greek Orthodox Christians in Crete, including decreases in saturated fat and increases in fruits, vegetables and dietary fibre ${ }^{(29-32)}$. It is unknown, however, if similarly beneficial nutritional shifts are experienced by Orthodox Christians who follow this practice in the USA, where culinary traditions and food environments differ substantially from those in Greece. After all, there are no formal church-regulated restrictions on the amounts of sugar, added fats or refined grains that can be consumed on the Lenten MDE-restricted diet. To date no known studies have attempted to quantify changes in the diet that occur among Orthodox Christians in the USA during Lent or test if their spiritually motivated restrictions on MDE products necessarily lead to what could be described as a healthier dietary pattern when compared with their pre-Lenten omnivorous diet.

The primary aim of the present study, therefore, was to measure diet before and during Lent among a sample of Orthodox Christians in the USA in order (1) to assess the degree to which intake of major plant-based foods, fish and total energy change in relation to temporary, spiritually motivated restrictions on consumption of MDE products and (2) to test whether Lenten MDE restrictions as practiced by Orthodox Christians in the USA are associated with a greater odds of meeting national dietary recommendations on both 'healthy' and 'unhealthy' plant-based foods. These analyses provide comparative data for understanding the practice and implications of OC MDE fasting among Orthodox Christians in the USA relative to what has previously been documented among Orthodox Christians in Greece ${ }^{(29-32)}$ and Egypt ${ }^{(33)}$.

\section{Methods}

\section{Study design and participants}

The present study followed participants during a 5- to 6-week period on their normal pre-Lenten diet between January and early March of 2016 and the subsequent MDE-restricted diet during OC Lent lasting from early March to late April 2016. Participants were recruited through oral and written announcements from eight Antiochian OC churches and one Greek OC church in the southern region of the USA; non-Orthodox Christians were also invited to join the study in effort to recruit individuals with a range of adherence to OC Lenten dietary restrictions. Eligibility was limited to men and non-pregnant, non-lactating women between the ages of 18 and 75 years who were born or raised in the USA or Canada. All participants provided informed consent, and all study protocols were approved by the Institutional Review Board of the University of Washington.

The sample size was determined by the feasibility of recruitment (a convenience sample), which lasted from September 2015 until one week prior to Lent in March 2016, ensuring that each participant had time to record $7 \mathrm{~d}$ of their pre-Lenten diet. Of the 141 volunteers who consented, 120 volunteers initiated study protocols, 114 completed the first (pre-Lenten) dietary assessments and 107 finished the second round of dietary assessments during the OC Lenten period (See online Supplementary Fig. S1 for participant flow chart). The stated reasons for participants not continuing with the study, if provided, were generally related to time constraints. The final sample size for analyses was ninety-nine after excluding individuals who had unreliably low $[<2092 \mathrm{~kJ}(<500 \mathrm{kcal})$ for females and $<3347 \mathrm{~kJ}(<800 \mathrm{kcal})$ for males] or high [ $>18828 \mathrm{~kJ}$ ( $>4500 \mathrm{kcal}$ ) for females and $>20920 \mathrm{~kJ}$ (>5000 kcal) for males] estimates of energy intake in either time period ( $n 2$ ), reported being on a strict weight loss regimen during the study period ( $n 2)$, made dietary changes during the Catholic period of Lent prior to OC Lent ( $n 1)$, already restricted all MDE products at baseline $(n 2)$, or reported a change in cholesterol- or diabetes-related medications during the study period ( $n 1$ ). We estimated that this sample size would provide us with $80 \%$ power at a Bonferroni-adjusted $\alpha$-level to detect at least a third- to half-serving change in each of the food groups examined in relation to MDE restrictions.

\section{Diet and nutrition assessment}

Diet was measured before and during Lent using both a validated 124-item self-administered FFQ ${ }^{(34)}$ and a 7-d food record (FR). The FFQ used in the present study was made available through the Nutrition Assessment Shared Resources of the Fred Hutchinson Cancer Research Center ${ }^{(35)}$ and has been validated against the average of four 24-h recalls and a 4-d FR for the measurement of energy intake and major nutrients ${ }^{(34)}$. The FFQ was administered 2-3 weeks before Lent and again in the last two weeks of Lent. For each FFQ, participants were asked to specify 
the frequency (never, once per month, two to three times per month, once per week, twice per week, three to four times per week, five to six times per week, once a day, or twice or more a day) and usual serving size (small, medium or large, with reference sizes for medium servings provided) of 106 food items and eighteen beverage items consumed over the previous 4-5 weeks. Thirteen additional adjustment questions asked participants about the kinds of added fats used regularly and the typical fat content of meat and dairy products consumed. Because the FFQ did not cover a comprehensive range of meat and dairy substitutes, participants received additional written instructions to count rice, almond or coconut milk as 'soya milk'; coconut oil as 'other oils'; almond cheese as 'tofu cheese'; and veggie burgers as 'tofu and tempeh' on the FFQ.

The FR used in the present study was 'undocumented', meaning they were entered and analysed as received in contrast to a 'documented' FR for which research staff review the completed FR with participants to correct any errors or omissions ${ }^{(36)}$. Two studies have demonstrated that, with adequate instruction, undocumented FR provide nutrient estimates highly correlated with those of documented $\mathrm{FR}^{(36,37)}$. In the present study, participants were provided an online video tutorial on how to complete the FR, and the FR booklets included detailed written instructions. The FR booklets were modelled after the undocumented multiple-day FR developed by the Nutrition Assessment Shared Resource of the Fred Hutchinson Cancer Research Center ${ }^{(38)}$. The booklets offered prompts to include information on the amount of food, method of preparation and brand name of food (if applicable). They also included example food entries, pages for entering recipes and guidelines for reporting portion size with pictures and tips for estimating food volumes using standard household objects as references. All participants were asked to complete seven consecutive days of recording during a week of their choice within the 4-5-week span preceding each FFQ administration. However, they were given the option to skip days and resume later if they experienced illness or if unusual circumstances substantially altered their eating in the middle of their self-designated recording period.

FFQ were reviewed for errors by the researcher (H. J. B.) and processed by the Nutrition Assessment Shared Resource of the Fred Hutchinson Cancer Research Center, using the 2015 version of the University of Minnesota Nutrition Data Systems for Research (NDSR) software ${ }^{(39)}$, to obtain measures of average daily consumption of major food groups, macro- and micronutrients, and energy content. The same software was used to enter and compute nutritional composition for the FR data. The food variables that were generated by this software utilise the MyPyramid Equivalent Database (MPED) ${ }^{(40)}$ for the FFQ and the Nutrition Coordinating Center (NCC) Food Group Serving Count System ${ }^{(39)}$ for the FR data. Estimates of macro- and micronutrients were measured by their mass (e.g. grams), and total energy intake was measured in kcal but is presented herein as $\mathrm{kJ}(1 \mathrm{kcal}=4 \cdot 184 \mathrm{~kJ})$. However, this nutritional software only provides measures of meat and fish in ounces (oz); eggs, grains, nuts and soya products in ounce-equivalents (oz-eq); fruit, vegetables, dairy products and legumes (not including soya products) in cup-equivalents (cup-eq).

All food and nutrient variables were standardised to $8368 \mathrm{~kJ}$ (2000 kcal). Percentage energy contents from proteins, fats and carbohydrates were obtained by multiplying the grams of each by $16.7 \mathrm{~kJ}$ ( $4 \mathrm{kcal}), 37.7 \mathrm{~kJ}$ (9 kcal) and $16.7 \mathrm{~kJ}$ ( $4 \mathrm{kcal}$ ), respectively, and dividing that estimate by total energy intake (which also included energy content from alcohol). Composite measures of participants' consumption of MDE products before Lent (MDE1 score) and during Lent (MDE2 score) were created by adding the number of servings/8368 $\mathrm{kJ}$ of MDE products consumed in each period. An MDE 'serving' was defined as $3 \mathrm{oz}$ (approximately $85 \mathrm{~g}$ ) of unprocessed meat, $2 \mathrm{oz}$ (approximately $57 \mathrm{~g}$ ) of processed meat, 1 cup-eq of dairy products (approximately $245 \mathrm{~g}$ milk or yogurt or approximately $48 \mathrm{~g}$ of cheese) or $2 \mathrm{oz}-\mathrm{eq}$ of eggs (approximately 2 eggs or $50 \mathrm{~g}$ ). The difference between the MDE1 and MDE2 scores was used as an estimate of the change in MDE servings between the normal (pre-Lenten) and MDE-restricted (Lenten) periods.

Servings of non-MDE foods were defined as $3 \mathrm{oz}$ (approximately $85 \mathrm{~g}$ ) of fish, $1 \mathrm{oz}-\mathrm{eq}$ (approximately $28 \mathrm{~g}$ ) of grains or soya products, 1 cup-eq (approximately $175 \mathrm{~g}$ ) of legumes, $1 \mathrm{oz}-\mathrm{eq}$ (approximately $15 \mathrm{~g}$ ) of nuts or seeds and 1 cup-eq (approximately $150 \mathrm{~g}$ ) of whole fruit, vegetables or white potatoes. Because gram weights of oz- and cup-eq of some foods (e.g. fruits and vegetables) can vary depending on their water content or form of consumption (e.g. cooked or raw), the gram conversions presented herein can be considered only rough estimates.

\section{Covariates}

Across the course of the study, participants completed three surveys to collect information about demographics; self-rated health status, existing health conditions; medication and supplement use; tobacco, alcohol and caffeine consumption; and general dietary preferences. Physical activity levels prior to and during Lent were estimated using the validated questionnaire developed for the Aerobics Center Longitudinal Study ${ }^{(41,42)}$. This questionnaire surveyed participants on their average weekly frequency, duration and speed (if relevant) of engagement in fifteen activities, including walking, household chores, yardwork, and included options to state other forms of physical activity not included in the original list. Activity-specific metabolic equivalent values (MET), which represent the ratio of the metabolic cost of performing the activity to a standardised $\mathrm{RMR}^{(43)}$, were multiplied by the minutes per week of reported engagement in each activity. MET for each activity were summed and divided by 60 to obtain a measure of weekly MET hours in each data collection period.

\section{Statistical analyses}

To assess how food composition changed in relation to reductions in MDE servings during Lent, multiple linear regression models with robust standard errors were used to regress the standardised Lenten servings of nine foods (fish, whole grains, refined grains, legumes, soya products, nuts and seeds, fruit, vegetables, white potatoes) on the change in MDE consumption while controlling for MDE1 score, baseline intake of the respective food being tested, baseline energy content, change in energy content, average weekly MET hours, change in weekly MET hours, and baseline BMI, age and sex. A Bonferroniadjusted $\alpha$-level of $0 \cdot 05 / 9=0.0055$ was used to assess statistical 
Table 1. Baseline demographic and lifestyle characteristics of study participants $(n$ 99)

(Mean values and ranges; percentages)

\begin{tabular}{|c|c|c|}
\hline & Mean & Range \\
\hline Age (years) & 46.7 & $19 \cdot 1-73 \cdot 2$ \\
\hline Baseline BMI $\left(\mathrm{kg} / \mathrm{m}^{2}\right)$ & $27 \cdot 3$ & $18 \cdot 1-43 \cdot 8$ \\
\hline Average weekly MET hours & $20 \cdot 1$ & $0-128 \cdot 4$ \\
\hline Male (\%) & \multicolumn{2}{|c|}{$42 \cdot 4$} \\
\hline Self-reported race as 'White or Caucasian' (\%) & \multicolumn{2}{|c|}{93.9} \\
\hline 4-year college degree or higher (\%) & \multicolumn{2}{|c|}{$91 \cdot 8$} \\
\hline Annual income $\geq \$ 100000^{*}(\%)$ & \multicolumn{2}{|c|}{$44 \cdot 7$} \\
\hline Orthodox Christian (\%) & \multicolumn{2}{|c|}{96.0} \\
\hline Self-rated health 'good' to 'excellent' (\%) & \multicolumn{2}{|c|}{89.9} \\
\hline Taking cholesterol or diabetes medications (\%) & \multicolumn{2}{|c|}{$14 \cdot 1$} \\
\hline Current smokers (\%) & \multicolumn{2}{|c|}{8.1} \\
\hline Reporting >7 alcohol drinks/week (\%) & \multirow{2}{*}{\multicolumn{2}{|c|}{$\begin{array}{r}24 \cdot 2 \\
5 \cdot 1\end{array}$}} \\
\hline Ovo-lacto-vegetarian or pescetarian (\%) & & \\
\hline
\end{tabular}

MET hours, metabolic equivalent values for moderate to vigorous physical activities. ${ }^{*}$ Excluding five individuals who did not report annual household income.

significance in these food-based models. The same multiple linear regression models were re-estimated with total energy content, fibre and categories of protein, fat, carbohydrates and twelve micronutrients; these analyses used a Bonferroniadjusted $\alpha$-level of $0 \cdot 05 / 25=0.002$ to assess statistical significance.

To test whether MDE restriction was associated with a greater likelihood of meeting national dietary recommendations, binary variables were created to indicate whether each individual met 2015-2020 Dietary Guidelines for Americans ${ }^{(44)}$ on total vegetables, green vegetables, red and orange vegetables, starchy and other vegetables, legumes, total fruit, whole grains, and nuts and soya products or staying below recommended thresholds for refined grains and added sugars. Multiple logistic regression models with robust standard errors were used to test whether a reduction in MDE servings was associated with the odds of meeting recommendations on intake for plant-sourced food categories. Logistic regression models controlled for the baseline consumption of the given food being tested, baseline MDE intake, baseline energy content, change in energy content, average weekly MET hours, change in weekly MET hours, and baseline BMI, age and sex. A Bonferroni-adjusted $\alpha$-level of $0 \cdot 05 / 10=0 \cdot 005$ was used to assess statistical significance in the logistic regression models.

The variation in the degree to which participants in our sample reduced their MDE consumption made direct comparisons with other OC study populations difficult. Hence, for the purpose of presenting data that could be compared with the pre-Lenten and Lenten dietary composition of other OC populations ${ }^{(29-32)}$, we described the food and nutritional composition of a subsample of thirty-six 'strict' MDE fasters, which we defined as those who, according to the FFQ data, decreased their MDE consumption by $\geq 2$ serving/d (mean: 3 serving) and were consuming $<1$ serving of MDE products during Lent.

All multivariate linear and logistic regression analyses conducted initially with FFQ data were repeated for the FR data (see Supplementary material). Analyses were conducted using StataSE 14.2 (StataCorp).

\section{Results}

Sample demographics, health characteristics and baseline dietary characteristics

The study sample was, on average, highly educated; the majority had received a minimum of a 4-year college degree and almost half reported an annual household income $\geq \$ 100000$ (Table 1). Four individuals in the sample did not identify as OC. The average BMI of participants was $27 \cdot 3 \mathrm{~kg} / \mathrm{m}^{2}$, and fourteen of individuals reported regularly taking medication for blood pressure ( $n$ 10), cholesterol ( $n$ 6) or diabetes ( $n$ 3).

Five individuals reported regularly consuming vegetarian ( $n$ 3) or pescetarian diets ( $n 2$ ). Overall, study participants were consuming an average of $3 \mathrm{MDE}$ servings/d prior to Lent, and they reduced their MDE consumption by an average of 1.7 servings and by as many as 4.9 servings (Table 2 ). Baseline consumption of refined grains was higher than the consumption of whole grains, on average, and participants were consuming just under 1 and 2 servings of whole fruits and vegetables, respectively. Prior to Lent, study participants were consuming an average of 17 of their energy as protein, 37 as fat and 45 as carbohydrates (Table 3). They were obtaining about $23 \mathrm{~g}$ (approximately $11.5 \mathrm{~g} / 1000 \mathrm{kcal}$ ) of fibre and an estimated $10 \%$ of their energy content in the form of added sugar. Average consumption of vitamin $\mathrm{D}$, Ca and $\mathrm{Mg}$ was lower at baseline than the respective RDA (Table 4). Baseline dietary characteristics among the subsample of strict fasters were comparable with those of the full sample (online Supplementary Tables S2-S4).

\section{Shifts in food and nutrient composition in relation to Lenten meat, dairy and egg restrictions}

When adjusting for baseline intake of each food, shifts in total energy and other covariates, only legumes, soya products, and nuts and seeds increased significantly in relation to FFQ estimates of MDE restrictions (Table 5). Specifically, each serving decrease in MDE products during Lent was associated with an average 0.09-serving (approximately $16 \mathrm{~g}$ ) increase in legumes (95\% CI 0.05, 0.13; $P<0 \cdot 0001$ ), a 0.19-serving (approximately $5 \mathrm{~g}$ ) increase in soya products (95\% CI $0 \cdot 11,0 \cdot 27 ; P<0.0001$ ) and a 0.54 -serving (approximately $8 \mathrm{~g}$ ) increase in nuts and seeds (95\% CI 0.31, 0.77; $P<0.0001$ ). The FR data corroborated these findings but also suggested that the approximate quarterserving (approximately $8 \mathrm{~g}$ ) increase in whole grains and tenth-serving (approximately $15 \mathrm{~g}$ ) increase in whole fruit in relation to each MDE serving reduction was statistically significant at the Bonferroni-adjusted $\alpha$-level (Figure 1; online Supplementary Table S5). When accounting for multiple comparisons, neither the FFQ nor the FR data provided evidence of a significant change in the consumption of fish, refined grains, vegetables or white potatoes in relation to restrictions on MDE consumption.

The FFQ data suggested that each serving decrease in MDE products during Lent was associated with an average change in total energy of $-478 \mathrm{~kJ}(-113 \mathrm{kcal} ; 95 \% \mathrm{CI}-745,-201 \mathrm{~kJ}$; $P=0.0008$ ) (Table 6). During Lent, energy intake among males and females was approximately $2443 \mathrm{~kJ}$ (584 kcal) and $1810 \mathrm{~kJ}$ 
Table 2. FFQ estimates of animal- and plant-based food intake before and during Lent $(n 99)^{\star}$

(Mean values and 5th and 95th percentiles)

\begin{tabular}{|c|c|c|c|c|c|c|c|c|c|c|c|c|}
\hline & \multicolumn{6}{|c|}{ Pre-Lent } & \multicolumn{6}{|c|}{ Lent } \\
\hline & \multicolumn{3}{|c|}{ Servings† } & \multicolumn{3}{|c|}{ Estimated gram amounts } & \multicolumn{3}{|c|}{ Servingst } & \multicolumn{3}{|c|}{ Estimated gram amounts } \\
\hline & Mean & $\begin{array}{c}\text { 5th } \\
\text { percentile }\end{array}$ & $\begin{array}{c}\text { 95th } \\
\text { percentile }\end{array}$ & Mean & $\begin{array}{c}\text { 5th } \\
\text { percentile }\end{array}$ & $\begin{array}{c}\text { 95th } \\
\text { percentile }\end{array}$ & Mean & $\begin{array}{c}\text { 5th } \\
\text { percentile }\end{array}$ & $\begin{array}{c}\text { 95th } \\
\text { percentile }\end{array}$ & Mean & $\begin{array}{c}\text { 5th } \\
\text { percentile }\end{array}$ & $\begin{array}{c}\text { 95th } \\
\text { percentile }\end{array}$ \\
\hline \multicolumn{13}{|l|}{ Animal-based foods } \\
\hline $\begin{array}{l}\text { Total MDE } \\
\text { servings }\end{array}$ & $3 \cdot 0$ & 1.3 & 4.9 & & & & 1.3 & 0 & $4 \cdot 6$ & & & \\
\hline Red meat & 0.7 & 0.03 & $2 \cdot 0$ & $59 \cdot 7$ & $2 \cdot 1$ & 168.5 & 0.2 & 0 & 0.9 & $13 \cdot 4$ & 0.5 & $75 \cdot 4$ \\
\hline Poultry & 0.5 & 0.04 & $1 \cdot 1$ & 38.6 & $3 \cdot 1$ & $90 \cdot 7$ & 0.1 & 0 & 0.9 & 11.9 & 0 & $73 \cdot 0$ \\
\hline Processed meat & 0.3 & 0.004 & 1.0 & $16 \cdot 3$ & 0.2 & $56 \cdot 7$ & 0.07 & 0 & 0.4 & 3.7 & 0 & $24 \cdot 0$ \\
\hline Fish and shellfish & 0.3 & 0 & 0.8 & $25 \cdot 1$ & 0.0 & 64.4 & 0.4 & 0 & 1.4 & $35 \cdot 4$ & 0 & $118 \cdot 3$ \\
\hline Milk & 0.5 & $0 \cdot 1$ & 1.4 & $119 \cdot 2$ & 20.0 & $341 \cdot 1$ & 0.3 & 0 & 1.4 & $79 \cdot 0$ & 3.9 & $340 \cdot 6$ \\
\hline Yogurt & 0.2 & 0 & $0 \cdot 7$ & 43.5 & 0 & $167 \cdot 2$ & $0 \cdot 1$ & 0 & 0.6 & 24.4 & 0 & $148 \cdot 3$ \\
\hline Cheese & 0.5 & 0.1 & $1 \cdot 1$ & 25.5 & 6.4 & $54 \cdot 1$ & 0.3 & 0 & 1.0 & 14.9 & 0.3 & $50 \cdot 2$ \\
\hline Eggs & 0.3 & 0.03 & 1.2 & 34.8 & 3.0 & $117 \cdot 9$ & 0.2 & 0 & 0.8 & $17 \cdot 5$ & 0.6 & $84 \cdot 3$ \\
\hline \multicolumn{13}{|l|}{ Plant-based foods } \\
\hline Whole grains & 1.5 & $0 \cdot 1$ & 4.5 & $42 \cdot 3$ & 1.9 & $127 \cdot 1$ & $2 \cdot 0$ & 0.1 & 5.5 & 55.8 & $2 \cdot 0$ & 154.5 \\
\hline Refined grains & $3 \cdot 7$ & 1.0 & $6 \cdot 8$ & 104.7 & $28 \cdot 0$ & $189 \cdot 9$ & 4.7 & 1.9 & $8 \cdot 3$ & $130 \cdot 4$ & $52 \cdot 6$ & $231 \cdot 2$ \\
\hline Legumes & 0.1 & 0.01 & 0.5 & $25 \cdot 0$ & 1.7 & $78 \cdot 8$ & 0.3 & 0.01 & 0.9 & 52.4 & 1.3 & $157 \cdot 8$ \\
\hline Soya products & 0.3 & 0 & $1 \cdot 1$ & $7 \cdot 3$ & 0 & $30 \cdot 1$ & 0.6 & 0 & $2 \cdot 1$ & $16 \cdot 6$ & 0 & $58 \cdot 6$ \\
\hline Nuts and seeds & 1.4 & 0 & $4 \cdot 4$ & $20 \cdot 4$ & 1.3 & $66 \cdot 6$ & $2 \cdot 2$ & 0.1 & 5.9 & $33 \cdot 3$ & $2 \cdot 2$ & $88 \cdot 7$ \\
\hline Fruitł & 0.9 & 0.1 & $2 \cdot 9$ & 134.0 & 8.7 & $441 \cdot 2$ & 1.2 & 0.1 & 3.2 & $177 \cdot 3$ & $15 \cdot 8$ & $487 \cdot 1$ \\
\hline Vegetables§ & 1.9 & 0.7 & 4.8 & 286.9 & 99.6 & 716.9 & $2 \cdot 6$ & 0.7 & 5.9 & $392 \cdot 3$ & $105 \cdot 6$ & $889 \cdot 1$ \\
\hline White potatoes & 0.4 & 0.1 & 0.9 & 55.9 & 11.5 & $129 \cdot 3$ & 0.5 & 0.1 & 1.1 & $71 \cdot 7$ & 11.5 & $159 \cdot 8$ \\
\hline
\end{tabular}

MDE, meat, dairy and egg.

${ }^{*}$ All food variables are standardised to $2000 \mathrm{kcal}(8368 \mathrm{~kJ})$.

† One serving of meat, poultry or fish $=3$ oz or approximately $84 \mathrm{~g}$; one serving of dairy product $=245 \mathrm{~g}$ milk or yogurt, approximately $48 \mathrm{~g}$ cheese; one serving of whole or refined grains = 1 oz-eq or approximately $28 \mathrm{~g}$; one serving of soya products $=1 \mathrm{oz}$-eq or approximately $28 \mathrm{~g}$; one serving of legumes $=1 \mathrm{cup}$-eq or approximately $175 \mathrm{~g}$ (cooked); one serving of nuts and seeds $=1 \mathrm{oz}$-eq or approximately $15 \mathrm{~g}$; one serving of fruit, vegetables or potatoes $=1$ cup-eq or approximately $150 \mathrm{~g}$. Gram conversions should only be interpreted as rough estimates, as the weight of cup- and oz-equivalents of many foods can depend on their water content and preparation method.

‡ Excludes fruit juices.

$\S$ Excludes white potatoes.

Table 3. FFQ estimates of energy and macronutrient intake before and during Lent $(n 99)^{\star}$

(Mean values and 5th and 95th percentiles)

\begin{tabular}{|c|c|c|c|c|c|c|}
\hline & \multicolumn{3}{|c|}{ Pre-Lent } & \multicolumn{3}{|c|}{ Lent } \\
\hline & Mean & 5th percentile & 95th percentile & Mean & 5th percentile & 95th percentile \\
\hline Energy intake (males, kJ/d, $n$ 42) & 9749 & 4907 & 16319 & 7306 & 4323 & 11811 \\
\hline Energy intake (females, $\mathrm{kJ} / \mathrm{d}, n$ 57) & 8273 & 3953 & 13487 & 6464 & 2810 & 11707 \\
\hline Protein $(g)$ & $85 \cdot 0$ & $59 \cdot 8$ & $123 \cdot 9$ & $70 \cdot 4$ & $52 \cdot 4$ & $96 \cdot 8$ \\
\hline Protein (\%E) & $17 \cdot 0$ & $12 \cdot 0$ & $24 \cdot 8$ & $14 \cdot 1$ & 10.5 & $19 \cdot 4$ \\
\hline Animal protein $(\mathrm{g})$ & $54 \cdot 9$ & 21.4 & 91.5 & $26 \cdot 5$ & 3.9 & $70 \cdot 1$ \\
\hline Animal protein (\%E) & 11.0 & $4 \cdot 3$ & $18 \cdot 3$ & $5 \cdot 3$ & 0.8 & $14 \cdot 0$ \\
\hline Vegetable protein (g) & $30 \cdot 0$ & $17 \cdot 4$ & $47 \cdot 7$ & 43.9 & 24.5 & $63 \cdot 1$ \\
\hline Vegetable protein (\%E) & $6 \cdot 0$ & 3.5 & 9.5 & $8 \cdot 8$ & 4.9 & $12 \cdot 6$ \\
\hline Total fat (g) & $82 \cdot 5$ & $58 \cdot 3$ & $110 \cdot 9$ & $73 \cdot 3$ & $46 \cdot 0$ & $106 \cdot 2$ \\
\hline Total fat (\%E) & $37 \cdot 1$ & $26 \cdot 2$ & 49.9 & $33 \cdot 0$ & 20.7 & $47 \cdot 8$ \\
\hline Saturated fat (g) & $26 \cdot 0$ & $16 \cdot 9$ & $34 \cdot 6$ & $18 \cdot 2$ & $9 \cdot 6$ & $30 \cdot 2$ \\
\hline Saturated fat (\%E) & $11 \cdot 7$ & $7 \cdot 6$ & $15 \cdot 6$ & $8 \cdot 2$ & $4 \cdot 3$ & $13 \cdot 6$ \\
\hline Trans-fat (g) & 2.4 & $1 \cdot 2$ & $4 \cdot 2$ & 1.8 & 0.5 & 3.6 \\
\hline Trans-fat (\%E) & $1 \cdot 1$ & 0.5 & 1.9 & 0.8 & 0.2 & 1.6 \\
\hline Monounsaturated fat (g) & $30 \cdot 3$ & $21 \cdot 1$ & $40 \cdot 8$ & $28 \cdot 5$ & $17 \cdot 0$ & $44 \cdot 4$ \\
\hline Monounsaturated fat (\%E) & $13 \cdot 6$ & 9.5 & $18 \cdot 4$ & $12 \cdot 8$ & $7 \cdot 6$ & $20 \cdot 0$ \\
\hline Polyunsaturated fat (g) & $18 \cdot 9$ & $13 \cdot 4$ & $26 \cdot 7$ & $20 \cdot 7$ & $13 \cdot 5$ & $29 \cdot 8$ \\
\hline Polyunsaturated fat (\%E) & $8 \cdot 5$ & $6 \cdot 1$ & $12 \cdot 0$ & $9 \cdot 3$ & $6 \cdot 1$ & $13 \cdot 4$ \\
\hline Carbohydrates (g) & $223 \cdot 5$ & $138 \cdot 1$ & 304.5 & $269 \cdot 9$ & $185 \cdot 1$ & $347 \cdot 4$ \\
\hline Carbohydrate (\%E) & $44 \cdot 7$ & $27 \cdot 6$ & 60.9 & $54 \cdot 0$ & $37 \cdot 0$ & 69.5 \\
\hline Total sugar (g) & $94 \cdot 7$ & $34 \cdot 1$ & $150 \cdot 4$ & $101 \cdot 1$ & $51 \cdot 6$ & $153 \cdot 4$ \\
\hline Total sugar (\%E) & $18 \cdot 9$ & $6 \cdot 8$ & $30 \cdot 1$ & $20 \cdot 2$ & $10 \cdot 3$ & 30.7 \\
\hline Added sugar (g) & $50 \cdot .9$ & 13.4 & 92.4 & $52 \cdot 7$ & $18 \cdot 7$ & 90.9 \\
\hline Added sugar (\%E) & $10 \cdot 2$ & $2 \cdot 7$ & $18 \cdot 5$ & $10 \cdot 5$ & 3.7 & $18 \cdot 2$ \\
\hline Alcohol $(g)$ & $10 \cdot 1$ & 0.0 & $49 \cdot 8$ & $7 \cdot 5$ & 0.0 & 28.5 \\
\hline Fibre $(\mathrm{g})$ & $22 \cdot 9$ & $13 \cdot 2$ & $37 \cdot 7$ & $32 \cdot 2$ & $16 \cdot 8$ & $54 \cdot 6$ \\
\hline
\end{tabular}

E\%, percentage energy.

${ }^{*}$ All nutrients in grams are standardised to $2000 \mathrm{kcal}(8368 \mathrm{~kJ})$. To convert to kcal, divide kJ by $4 \cdot 184$. 
Table 4. FFQ estimates of micronutrient intake before and during Lent $(n 99)^{\star}$

(Mean values and 5th and 95th percentiles)

\begin{tabular}{|c|c|c|c|c|c|c|c|}
\hline & \multicolumn{3}{|c|}{ Pre-Lent } & \multicolumn{3}{|c|}{ Lent } & \multirow[b]{2}{*}{ RDA or Al† } \\
\hline & Mean & 5th percentile & 95th percentile & Mean & 5th percentile & 95th percentile & \\
\hline $\mathrm{Na}(\mathrm{mg})$ & 3384.8 & $2461 \cdot 2$ & $4487 \cdot 6$ & 3605.9 & 2538.5 & $5354 \cdot 3$ & $1500 \mathrm{mg} \ddagger$ \\
\hline $\mathrm{K}(\mathrm{mg})$ & 3022.6 & 2021.3 & 4319.4 & $3405 \cdot 6$ & 2383.4 & $4968 \cdot 1$ & $4700 \mathrm{mg} \ddagger$ \\
\hline Vitamin $\mathrm{A}(\mu \mathrm{g})$ & $951 \cdot 1$ & 387.6 & 2384.6 & $1000 \cdot 9$ & 353.1 & $2448 \cdot 8$ & $900 \mu \mathrm{g}(\mathrm{M}), 700 \mu \mathrm{g}(\mathrm{F})$ \\
\hline Folate $(\mu \mathrm{g})$ & $482 \cdot 7$ & $307 \cdot 8$ & $671 \cdot 0$ & 639.0 & 393.6 & $1011 \cdot 2$ & $400 \mu \mathrm{g}$ \\
\hline Vitamin $B_{6}(m g)$ & $2 \cdot 0$ & 1.4 & $2 \cdot 8$ & $2 \cdot 1$ & 1.4 & 3.4 & $1.3 \mathrm{mg}$ \\
\hline Vitamin $B_{12}(\mu \mathrm{g})$ & $5 \cdot 3$ & $2 \cdot 8$ & $9 \cdot 2$ & 4.6 & 1.0 & $10 \cdot 0$ & $2 \cdot 4 \mu \mathrm{g}$ \\
\hline Vitamin C (mg) & 103.9 & 31.4 & 237.9 & 134.9 & 51.8 & 269.5 & $90 \mathrm{mg}(\mathrm{M}), 75 \mathrm{mg}(\mathrm{F})$ \\
\hline Vitamin D $(\mu \mathrm{g})$ & 5.5 & $2 \cdot 4$ & $10 \cdot 8$ & 3.9 & 0.5 & $10 \cdot 6$ & $15 \mu \mathrm{g}$ \\
\hline Vitamin E (mg) & $10 \cdot 7$ & $5 \cdot 1$ & $17 \cdot 7$ & $13 \cdot 9$ & 7.9 & $21 \cdot 7$ & $15 \mathrm{mg}$ \\
\hline Vitamin $\mathrm{K}(\mu \mathrm{g})$ & 193.2 & 58.2 & 608.8 & 237.9 & 67.5 & $846 \cdot 4$ & $120 \mu \mathrm{g}(\mathrm{M}), 90 \mu \mathrm{g}(\mathrm{F}) \ddagger$ \\
\hline $\mathrm{Ca}(\mathrm{mg})$ & $910 \cdot 7$ & 547.4 & $1350 \cdot 7$ & 888.6 & $503 \cdot 4$ & $1417 \cdot 1$ & $1000 \mathrm{mg}$ \\
\hline $\mathrm{Fe}(\mathrm{mg})$ & $13 \cdot 7$ & $10 \cdot 2$ & $19 \cdot 1$ & $16 \cdot 6$ & $10 \cdot 7$ & $25 \cdot 5$ & $8 \mathrm{mg}(\mathrm{M}), 18 \mathrm{mg}(\mathrm{F})$ \\
\hline $\mathrm{Mg}(\mathrm{mg})$ & 341.5 & 233.1 & 459.3 & $417 \cdot 0$ & 303.0 & 570.9 & $420 \mathrm{mg}(\mathrm{M}), 320 \mathrm{mg}(\mathrm{F})$ \\
\hline $\operatorname{Se}(\mu \mathrm{g})$ & $126 \cdot 5$ & 91.4 & $169 \cdot 5$ & $123 \cdot 4$ & 88.6 & $168 \cdot 3$ & $55 \mu \mathrm{g}$ \\
\hline $\mathrm{Zn}(\mathrm{mg})$ & $12 \cdot 1$ & $8 \cdot 7$ & $18 \cdot 2$ & 11.8 & 8.3 & 17.9 & $11 \mathrm{mg}(\mathrm{M}), 8 \mathrm{mg}(\mathrm{F})$ \\
\hline
\end{tabular}

RDA, Recommended Dietary Allowance; Al, Adequate Intake; M, male; F, female.

${ }^{*}$ All nutrients are standardised to $2000 \mathrm{kcal}(8368 \mathrm{~kJ})$.

† Based on sex-specific values of RDA or Al specified by the Food and Nutrition Board of the Institute of Medicine for 19- to 50-year-old adults( ${ }^{(88)}$.

$\ddagger$ Value is for the Al as opposed to the RDA.

Table 5. Multiple linear regression results for additive change in major non-meat, dairy and egg (MDE) foods in relation to a one-serving reduction in MDE products as estimated by FFQ data $(n 99) \dagger$ ( $\beta$-Coefficients and $95 \%$ confidence intervals)

\begin{tabular}{lcccccc}
\hline & \multicolumn{2}{c}{ Servings $\neq$} & & \multicolumn{2}{c}{ Gram estimates } & \\
\cline { 2 - 3 } & $\beta$ & $95 \% \mathrm{Cl}$ & & $\beta$ & $95 \% \mathrm{Cl} n$ & $P$ \\
\hline Fish & 0.01 & $-0.04,0.07$ & & 1.12 & $-3.64,6.16$ & 0.61 \\
Whole grains & 0.26 & $0.06,0.46$ & & 7.28 & $1.68,12.88$ & 0.01 \\
Refined grains & 0.28 & $0.03,0.52$ & & 7.84 & $0.84,14.56$ & 0.03 \\
Legumes & 0.09 & $0.05,0.13$ & & 15.75 & $8.75,22.75$ & $<0.0001^{*}$ \\
Soya products & 0.19 & $0.11,0.27$ & & 5.32 & $3.08,7.56$ & $<0.0001^{*}$ \\
Nuts and seeds & 0.54 & $0.31,0.77$ & & 7.56 & $4.34,10.78$ & $<0.0001^{*}$ \\
Fruit§ & 0.08 & $-0.06,0.22$ & & 12.0 & $-9.0,33.0$ & 0.25 \\
Vegetablesll & 0.17 & $0,0.34$ & & 25.50 & $0,51.0$ & 0.04 \\
White potatoes & 0.02 & $-0.02,0.06$ & 3.0 & $-3.0,9.0$ & 0.35 \\
\hline
\end{tabular}

MET, metabolic equivalent values.

* Significant at the Bonferroni-adjusted $\alpha$-level of 0.0055 .

† Results from multiple linear regression models controlling for baseline MDE consumption, baseline consumption of the dependent variable of interest, baseline energy intake, the change in energy content, average MET hours, change in MET hours, age, sex and baseline BMI; using robust standard errors. $\beta$-Coefficients represent the additive difference in each variable of interest during Lent relative to a one-serving decrease in MDE products. All food are variables standardised to 2000 $\mathrm{kcal}(8368 \mathrm{~kJ})$.

‡ One serving of fish $=3$ oz or approximately $84 \mathrm{~g}$; one serving of whole or refined grains $=1 \mathrm{oz}-\mathrm{eq}$ or approximately $28 \mathrm{~g}$; one serving of soya products $=1 \mathrm{oz}-\mathrm{eq}$ or approximately $28 \mathrm{~g}$; one serving of legumes $=1$ cup-eq or approximately $175 \mathrm{~g}$ (cooked); one serving of nuts and seeds $=1 \mathrm{oz}$-eq or approximately $14 \mathrm{~g}$; one serving of fruit, vegetables or potatoes $=1 \mathrm{cup}$-eq or approximately $150 \mathrm{~g}$. Gram conversions should only be interpreted as rough estimates, as the weight of cup-and oz-equivalents of many foods can depend on their water content and preparation method.

$\S$ Excluding fruit juice.

II Excluding white potatoes.

(433 kcal) lower, respectively, among the sample as a whole (Table 3) and approximately $2377 \mathrm{~kJ}(568 \mathrm{kcal})$ and $2548 \mathrm{~kJ}$ (609 kcal) lower, respectively, among the strict MDE faster subsample (online Supplementary Table S3). Each serving reduction in MDE products was also associated with an average $-7 \cdot 1 \mathrm{~g}$ change in total protein intake (95\% CI -8.9, -5.4;
$P<0.0001),-14.2 \mathrm{~g}$ change in animal protein intake $(95 \%$ CI $-15.9,-12.5 ; P<0.0001)$ and $7.0 \mathrm{~g}$ increase in plant protein (95\% CI 5.9, 8.2; $P<0.0001$ ) (Table 4). A serving decrease in MDE products was further associated with an average $-4.7 \mathrm{~g}$ shift in total fat $(95 \% \mathrm{CI}-6 \cdot 8,-2 \cdot 7 ; P<0 \cdot 0001),-3.7 \mathrm{~g}$ shift in saturated fat intake (95\% CI $-4.3,-3.1 ; P<0.0001)$ and $-0.4 \mathrm{~g}$ change in trans-fat intake $(95 \% \mathrm{CI}-0.5,-0.3 ; P<0.0001)$.

Carbohydrate intake increased by an average of $19.0 \mathrm{~g}(95 \%$ CI 14.1, 23.9; $P<0.0001)$ in relation to each serving decrease in MDE products. There was no indication that total or added sugar consumption changed in relation to MDE restriction. Dietary fibre intake increased by an average of $3.8 \mathrm{~g}$ (95\% CI 2.6, 4.9; $P<0.0001)$ for each serving reduction in MDE consumption. During Lent, the sample as a whole was consuming an average of $9.3 \mathrm{~g}(4.7 \mathrm{~g} / 1000 \mathrm{kcal})$ more fibre (Table 3), while the strict MDE fasters were consuming approximately $15.6 \mathrm{~g}$ $(7 \cdot 8 \mathrm{~g} / 1000 \mathrm{kcal})$ more fibre (online Supplementary Table S3).

The micronutrient changes that were significantly associated with MDE reductions at the adjusted $\alpha$-level included the average $-1 \mu \mathrm{g}(95 \% \mathrm{CI}-1 \cdot 2,-0.7 ; P<0.0001)$ change in vitamin $\mathrm{B}_{12}$ intake, $-1.7 \mu \mathrm{g}(95 \% \mathrm{CI}-2.2,-1.2 ; P<0.0001)$ change in vitamin D intake, $-123.5 \mathrm{mg}(95 \% \mathrm{CI}-169 \cdot 8,-77 \cdot 2 ; P<0.0001)$ change in $\mathrm{Ca}$ intake and $-0.7 \mathrm{mg} / 8368 \mathrm{~kJ}(95 \% \mathrm{CI}-1 \cdot 1,-0 \cdot 3$; $P<0.0015)$ change in $\mathrm{Zn}$ intake. The only micronutrient that significantly increased in relation to the MDE changes was $\mathrm{Mg}$, which was estimated to increase by an average of $23.6 \mathrm{mg}$ (95\% CI 13.0, 34.2; $P<0 \cdot 0001$ ) in relation to each serving decrease in MDE consumption. During Lent, approximately one-third of the strict MDE fasters were not meeting the RDA for vitamin $\mathrm{B}_{12}$ or $\mathrm{Zn}$, and only $20 \%$ were meeting the RDA for Ca (online Supplementary Table S4).

The estimated changes in macronutrient intake were similar across the FFQ and FR data, except that the FR data suggested the reduction in energy intake was much smaller $(-113 v$. $473 \mathrm{~kJ}$ ) and not significant (online Supplementary Table S6). The FR data also suggested there might be a significant increase in 
FFQ

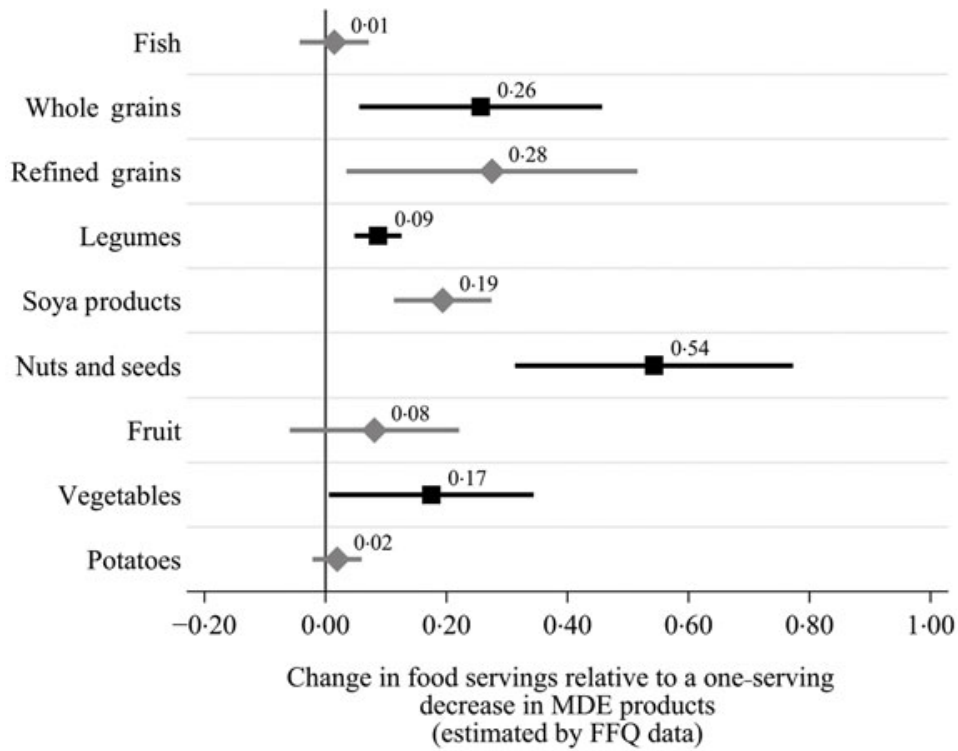

7-Day FR*

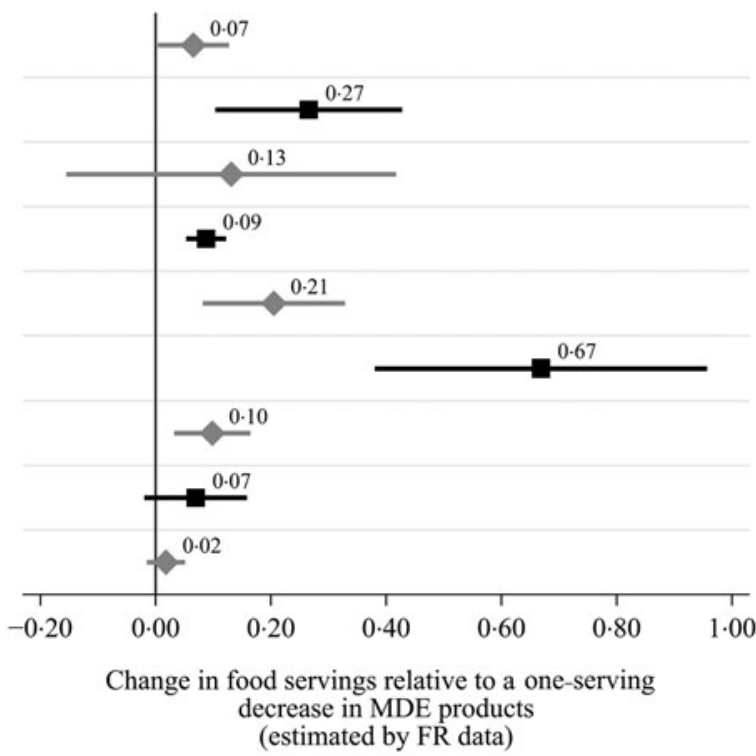

Fig. 1. Change in fish- and plant-based foods relative to a one-serving reduction in meat, dairy and egg (MDE) products: comparison of results with FFQ and 7-d food record (FR) data. Multiple linear regression analyses controlling for MDE1 score, baseline consumption of the dependent variable of interest, baseline energy intake, the change in energy content, average metabolic equivalent value (MET) hours, change in MET hours, age, sex and baseline BMI, $n 99$. $\beta$-Coefficients represent the additive difference in a serving of each variable of interest during Lent relative to a one-serving decrease in MDE products. All foods are variables standardised to $2000 \mathrm{kcal}$ $(8368 \mathrm{~kJ})$. One serving of meat, poultry or fish $=3 \mathrm{oz}$ or approximately $84 \mathrm{~g}$; one serving of whole or refined grains $=1 \mathrm{oz}$-eq or approximately $28 \mathrm{~g}$; one serving of soya products $=1 \mathrm{oz}$-eq or approximately $28 \mathrm{~g}$; one serving of legumes $=1$ cup-eq or approximately $175 \mathrm{~g}$ (cooked); one serving of nuts and seeds $=1 \mathrm{oz}$-eq or approximately $15 \mathrm{~g}$; one serving of fruit, vegetables or potatoes $=1$ cup-eq or approximately $150 \mathrm{~g}$. ${ }^{*}$ Excluding five participants with incomplete FR data.

polyunsaturated fat, folate and Fe but no significant change in $\mathrm{Zn}$ in relation to MDE restriction. Neither the FFQ nor the FR data provided evidence at the Bonferroni-adjusted $\alpha$-level for an association between MDE restriction and shifts in monounsaturated fat, total sugars, $\mathrm{Na}, \mathrm{K}$, vitamin $\mathrm{B}_{6}$, vitamin $\mathrm{K}$ or Se.

\section{Change in likelihood of meeting dietary guidelines}

Each serving reduction in MDE consumption during Lent was associated with an estimated 2.4-fold (95\% CI 1.3, 4.1; $P=0.003)$ and 3 -fold (95\% CI 1.5, 5.9; $P=0.002)$ increase in the respective odds of meeting dietary recommendations on the consumption of non-soya legumes and the intake of nuts and soya products (Table 7). There was no indication from the FFQ data, however, that MDE restriction increased the odds of meeting recommendations on other vegetables, fruit or whole grains. In fact, the FFQ data indicated that during Lent only $22 \cdot 2$ and $25.0 \%$ of strict MDE fasters met recommendations on fruit and whole grains, respectively. Moreover, 80.6 and $61.1 \%$ of strict MDE fasters continued to consume more than the recommended amounts of refined grains and added sugars, respectively, during Lent. The FR data mostly confirmed these findings, though the increase in the odds of meeting recommendations on legume consumption was not significant at the Bonferroni-adjusted $\alpha$-level (online Supplementary Table S7).

\section{Discussion}

To our knowledge, this is the first-known study to quantify the dietary changes experienced by Orthodox Christians in the USA during their Lenten spiritually motivated MDE fast and explore if their odds of meeting national dietary recommendations on plant-based foods increase in relation to MDE restriction. Among this OC sample, both FFQ and 7-d FR data provided evidence of some potentially beneficial changes in dietary composition in relation to MDE restriction, such as small but significant increases in non-soya legumes, soya products, and nuts and seeds. Including more of these foods in the diet may help reduce blood lipid levels and improve glycaemic control $^{(45-50)}$, though such benefits would arguably depend on baseline diet and on which foods the nuts, seeds, legumes and soya products displace. It is unclear whether the approximately 0.09-serving increase in legumes observed in this sample in relation to 1-serving decrease in MDE products would have a substantial effect on blood lipids or glucose control, especially considering that approximately one-third of strict MDE fasters were still not meeting national guidelines on weekly legume consumption. The combined increases in soya products and nuts and seeds, however, did result in most of the strict fasters meeting recommendations on the consumption of those foods. In fact, both dietary instruments indicated that strict MDE fasters who decreased their MDE consumption by an average of 3 serving/d were consuming approximately $0 \cdot 6-0 \cdot 7$ serving (approximately $17-20 \mathrm{~g}$ ) more soya products and $1.4-1.8$ serving (approximately 20-25 g) more nuts and seeds per $8368 \mathrm{~kJ}$ (2000 kcal). When controlling for baseline dietary characteristics and change in energy content, only the FR data provided evidence that the approximately $0 \cdot 8$-serving (approximately $22 \mathrm{~g}$ ) increase in whole grains and approximately $0 \cdot 3$-serving (approximately $45 \mathrm{~g}$ ) increase in whole fruit estimated for a 3-serving/d decrease in MDE products were statistically significant. 
Table 6. Multiple linear regression results for change in energy, macronutrients and micronutrients in relation to a one-serving reduction in meat, dairy and egg (MDE) products as estimated by FFQ data $(n 99) \dagger$ ( $\beta$-Coefficients and $95 \%$ confidence intervals)

\begin{tabular}{|c|c|c|c|}
\hline & $\beta$ & $95 \% \mathrm{Cl}$ & $P$ \\
\hline Energy $(\mathrm{kJ}) \ddagger$ & $-472 \cdot 8$ & $-745,-201$ & $0.0008^{*}$ \\
\hline \multicolumn{4}{|l|}{ Macronutrients } \\
\hline Protein $(\mathrm{g})$ & $-7 \cdot 1$ & $-8 \cdot 9,-5 \cdot 4$ & $<0.0001^{*}$ \\
\hline Animal protein $(\mathrm{g})$ & $-14 \cdot 2$ & $-15 \cdot 9,-12 \cdot 5$ & $<0.0001^{*}$ \\
\hline Vegetable protein $(\mathrm{g})$ & $7 \cdot 0$ & $5 \cdot 9,8 \cdot 2$ & $<0.0001^{*}$ \\
\hline Total fat $(\mathrm{g})$ & -4.7 & $-6 \cdot 8,-2 \cdot 7$ & $<0.0001^{*}$ \\
\hline Saturated fat $(\mathrm{g})$ & -3.7 & $-4 \cdot 3,-3 \cdot 1$ & $<0.0001^{*}$ \\
\hline Trans-fat (g) & -0.4 & $-0.5,-0.3$ & $<0.0001^{*}$ \\
\hline Monounsaturated fat $(\mathrm{g})$ & -0.6 & $-1.6,0.5$ & 0.32 \\
\hline Polyunsaturated fat $(\mathrm{g})$ & 0.6 & $-0.3,1.4$ & 0.19 \\
\hline Carbohydrates (g) & $19 \cdot 0$ & $14.1,23.9$ & $<0.0001^{*}$ \\
\hline Total sugar (g) & $1 \cdot 3$ & $-2 \cdot 9,5 \cdot 4$ & 0.54 \\
\hline Added sugar ( $(\mathrm{g})$ & 3.3 & $0.2,-6 \cdot 4$ & 0.04 \\
\hline Fibre (g) & 3.8 & $2 \cdot 6,4.9$ & $<0.0001^{*}$ \\
\hline \multicolumn{4}{|l|}{ Micronutrients } \\
\hline $\mathrm{Na}(\mathrm{mg})$ & 38.0 & $-74.5,150.5$ & 0.50 \\
\hline $\mathrm{K}(\mathrm{mg})$ & $72 \cdot 4$ & $-28 \cdot 9,173 \cdot 8$ & 0.16 \\
\hline Folate $(\mu \mathrm{g})$ & $27 \cdot 7$ & $5 \cdot 6,49 \cdot 7$ & 0.02 \\
\hline Vitamin $\mathrm{B}_{6}(\mathrm{mg})$ & -0.03 & $-0.1,0.1$ & 0.41 \\
\hline Vitamin $\mathrm{B}_{12}(\mu \mathrm{g})$ & -1.0 & $-1 \cdot 2,-0.7$ & $<0.0001^{*}$ \\
\hline Vitamin D $(\mu \mathrm{g})$ & $-1 \cdot 7$ & $-2 \cdot 2,-1 \cdot 2$ & $<0.0001^{*}$ \\
\hline Vitamin $\mathrm{K}(\mu \mathrm{g})$ & $-1 \cdot 1$ & $-32 \cdot 3,30 \cdot 1$ & 0.95 \\
\hline $\mathrm{Ca}(\mathrm{mg})$ & -123.5 & $-169 \cdot 8,-77 \cdot 2$ & $<0.0001^{*}$ \\
\hline $\mathrm{Fe}(\mathrm{mg})$ & 0.8 & $0.2,1.3$ & 0.005 \\
\hline $\mathrm{Mg}(\mathrm{mg})$ & 23.6 & $13 \cdot 0,34 \cdot 2$ & $<0.0001^{*}$ \\
\hline $\operatorname{Se}(\mu \mathrm{g})$ & -4.7 & $-8 \cdot 6,-0.8$ & 0.02 \\
\hline $\mathrm{Zn}(\mathrm{mg})$ & -0.7 & $-1 \cdot 1,-0.3$ & $0.002^{*}$ \\
\hline
\end{tabular}

MET, metabolic equivalent values.

${ }^{*}$ Significant at the Bonferroni-adjusted $\alpha$-level of 0.002 .

† Results from multiple linear regression models controlling for MDE1 score, baseline consumption of the dependent variable of interest, baseline energy intake, the change in energy content, average MET hours, change in MET hours, age, sex and baseline $\mathrm{BMl}$; using robust standard errors. $\beta$-Coefficients represent the difference in each nutrient relative to a one-serving decrease in MDE products. All nutrients are standardised to $2000 \mathrm{kcal}(8368 \mathrm{~kJ})$. To convert to kcal, divide kJ by 4.184 .

$\ddagger$ Controlling for same covariates with the exception of change in energy content.

As expected, these composite dietary shifts during Lent also resulted in significant reductions in the contribution of total and animal proteins and total and saturated fats to total energy intake and an increase in vegetable protein, total carbohydrates and dietary fibre. Additionally, the data suggested that strict MDE fasters experienced a drop in total energy intake (approximately 2380 and $2550 \mathrm{~kJ}$ for males and females during Lent) that was substantially larger than the approximate $753-870 \mathrm{~kJ}$ decrease observed in previous studies of OC MDE restriction ${ }^{(51)}$. However, only the FFQ data estimated the shift in energy to be significantly associated with MDE reductions, suggesting that either there was a widespread reduction in energy content among the sample or there was greater underreporting of food intake in the 7-d FR.

In addition to some dietary improvements observed during Lent in this sample of Orthodox Christians, the present study demonstrated how easy it is in the USA to substantially reduce MDE intake and (1) still not consume recommended amounts of all nutritious plant-based foods and (2) overconsume less healthy plant-based foods high in refined grains and added sugars. Neither dietary data source provided evidence that restricting MDE products increased the odds of meeting dietary recommendations on total, green or red/orange vegetables, whole grains or fruit. Furthermore, even though multivariate analyses did not provide consistent or significant evidence across the data sources for an increase in refined grains, the strict MDE fasters were consuming more than recommended daily amounts of refined grains during Lent. Similarly, although added sugar consumption did not appear to increase substantially during Lent, an estimated $31 \%$ (FR data) to $61 \%$ (FFQ data) of strict fasters were obtaining more than $10 \%$ of their total energy in the form of added sugar.

As none of the dietary changes observed in the present study occurred in isolation, the potential health implications of these findings are far from straightforward. Randomised controlled trials suggest that vegetarian and vegan diets may promote weight loss, improve glycaemic control, and lower total and LDLcholesterol $^{(52-54)}$. However, it is not entirely clear to what degree any health benefits of vegetarian and vegan diet patterns are due to the omission of meat and saturated fat, the increase in nutrientand fibre-rich plant-based foods typically prescribed in such trials, the reduction in total energy content or all of the above. After all, even low-carbohydrate or Atkins-type diets ${ }^{(55-57)}$ and so-called Palaeolithic dietary intervention studies ${ }^{(58-61)}$ have demonstrated that improvements in measures of body fat, glycaemic control, TAG and blood lipid ratios are achievable without restricting meat, so long as highly refined and processed grains and sugars are eliminated and replaced with mostly vegetables, fruits, nuts and seeds. In contrast, suboptimal intake of whole grains relative to refined grains ${ }^{(62-65)}$, low fruits and vegetable consumption $^{(62,66-69)}$, and excess intake of added sugars $^{(28,62,70-72)}$ tend to be associated with increased risk of weight gain, dyslipidaemia and cardiometabolic-related morbidity and mortality. In fact, replacing saturated fats with refined grains and added sugars may worsen blood lipid profiles ${ }^{(73-75)}$, and recent studies have suggested that low-meat diets may confer no cardiometabolic health benefit if they contain high amounts of refined grains, added sugars and fried potato products $^{(23,24,76)}$. Thus, it is unclear if any health benefits from small increases in only some healthy plant-based foods, as observed in this sample, would outweigh any detrimental effects of continued excess consumption of refined grains and sugars.

These findings demonstrate why it is important to pay attention not only to macro- and micronutrient changes that occur in relation to MDE restrictions but also to changes in the quality of foods being consumed in place of MDE products. As expected, Orthodox Christians who reduced their consumption of MDE products during Lent experienced substantial drops in energy intake; consumed significantly lower quantities of total and animal proteins and total and saturated fats; and consumed more vegetable protein, total carbohydrates and dietary fibre. These are generally viewed to represent beneficial dietary changes. Yet, when put in the context of the overall changes in food composition, it becomes clear that significant changes in macronutrient composition do not necessarily translate into a substantially higher quality diet.

Along similar lines, studies among Greek Orthodox Christians have highlighted the potential healthfulness of MDE fasting, as it consistently results in a reduction in energy content and saturated fat and increase in fibre ${ }^{(29-32)}$. However, only two studies have actually documented the foods 
Table 7. Odds of meeting US Department of Agriculture dietary recommendations on plant-based foods in relation to a one-serving reduction in meat, dairy and egg (MDE) products as estimated by FFQ data $(n$ 99)

\begin{tabular}{|c|c|c|c|c|c|c|}
\hline Food group & $\begin{array}{l}\text { Recommended amount per } \\
2000 \mathrm{kcal}(8368 \mathrm{~kJ})\end{array}$ & $\begin{array}{l}\text { Approximate gram } \\
\text { amounts }^{*}\end{array}$ & OR† & $95 \% \mathrm{Cl}$ & $P$ & $\begin{array}{l}\text { 'Strict' MDE fasters } \\
\text { meeting national dietary } \\
\text { recommendations (\%) }\end{array}$ \\
\hline All vegetables $\ddagger$ & $21 / 2$ cup-eq/d & $375 \mathrm{~g} / \mathrm{d}$ & 1.31 & $0 \cdot 81,2 \cdot 10$ & 0.27 & $72 \cdot 2$ \\
\hline Dark green vegetables & $11 \frac{1}{2}$ cup-eq/week & $225 \mathrm{~g} /$ week & 1.31 & $0.74,2.31$ & 0.35 & $66 \cdot 7$ \\
\hline Red and orange vegetables & $51 / 2$ cup-eq/week & $825 \mathrm{~g} /$ week & 1.47 & $1 \cdot 00,2 \cdot 17$ & 0.05 & $61 \cdot 1$ \\
\hline Legumes (beans and peas) & $11 \frac{1}{2}$ cup-eq/week & $225 \mathrm{~g} /$ week & $2 \cdot 35$ & $1 \cdot 34,4 \cdot 11$ & 0.003 & $66 \cdot 7$ \\
\hline Starchy vegetables§ & 5 cup-eq/week & $750 \mathrm{~g} /$ week & 1.04 & $0.67,1.62$ & 0.86 & $30 \cdot 6$ \\
\hline Other vegetables & 4 cup-eq/week & $600 \mathrm{~g} /$ week & 1.36 & $0.84,2 \cdot 20$ & 0.21 & $77 \cdot 8$ \\
\hline FruitsII & 2 cup-eq/d & $300 \mathrm{~g} / \mathrm{d}$ & 1.06 & $0.51,2.19$ & 0.87 & $22 \cdot 2$ \\
\hline \multicolumn{7}{|l|}{ Grains } \\
\hline Whole grains & $\geq 3$ oz-eq/d & $84 \mathrm{~g} / \mathrm{d}$ & $2 \cdot 37$ & $0.84,6.74$ & 0.11 & $25 \cdot 0$ \\
\hline Refined grains & $\leq 3$ oz-eq/d & $84 \mathrm{~g} / \mathrm{d}$ & 1.31 & $0.61,2.82$ & 0.49 & 19.4 \\
\hline Nuts, seeds, soya products & $\overline{5}$ oz-eq/week & $\begin{array}{l}70 \mathrm{~g} / \text { week nuts or } \\
140 \mathrm{~g} / \text { week soya } \\
\text { products }\end{array}$ & 2.96 & $1.48,5.90$ & 0.002 & 94.4 \\
\hline Added sugars & $<10 \%$ of total energy content & & 0.80 & $0.53,1.22$ & 0.30 & 38.9 \\
\hline
\end{tabular}

MET, metabolic equivalent values.

* Gram conversions should only be interpreted as rough estimates, as the weight of cup- and oz-equivalents of many foods can depend on their water content and preparation method. † OR represent the ratio of the odds of meeting recommended intake during Lent for the given category relative to a serving decrease in MDE products, controlling for MDE1 score, baseline intake of each food/food group of interest, baseline energy intake, change in energy content, average MET, change in MET, age, sex and baseline BMI.

$\ddagger$ Includes legumes.

$\S$ Includes white potatoes.

II Excluding fruit juices.

consumed by Greek Orthodox Christians during MDE fasting periods relative to non-fasting periods ${ }^{(29,30)}$. One study reported an increase in legume intake during MDE fasting periods ${ }^{(30)}$ while another reported a decrease ${ }^{(29)}$, and fruit and vegetable intake either did not change significantly ${ }^{(30)}$ or was higher during the MDE fasting period only relative to a control (non-fasting) group ${ }^{(29)}$. Both studies reported no change in daily intake of bread, cereal and sweets ${ }^{(29,30)}$. It is possible that the modest changes in food composition reported in these studies may have been interpreted differently, had the estimates been standardised to total energy intake or had included adjustment for baseline intake. However, because Greek Orthodox Christians are also described as consuming a diet higher in legumes, fruits and vegetables in general they may also experience less of a shift in food composition than Orthodox Christians in the USA, where the typical cuisine includes fewer healthy plant-based foods. Further research is needed among OC populations around the world to investigate the degree to which the reductions in energy content and saturated fat and increases in fibre experienced during MDE fasting periods are also accompanied by increases in healthy plant-based foods as opposed to less healthy refined and sugar-laden plant-based foods.

Some US-based vegetarian or vegan diet intervention studies have observed changes in protein, total fat, saturated fat and carbohydrate are comparable with those observed in this OC study sample during Lent ${ }^{(77,78)}$, but low-fat vegan diets often lead to even more dramatic shifts in total fat, saturated fat, protein and fibre $^{(76,79-82)}$ than those noted among OC MDE fasters. Notably, the average $1 \cdot 6$ - and 2.2-serving/d increase in fruit and vegetable intake, respectively, observed in one low-fat vegan intervention study $^{(79)}$ was substantially higher than the respective $0 \cdot 6$ - and $1 \cdot 0$-serving $/ 8368 \mathrm{~kJ}$ increase in fruits and vegetables observed in the sample of the present study during the Lenten period of MDE restriction. These larger differences in the consumption of healthy plant-based foods noted in intervention studies could be attributed to the additional nutritional guidance participants of such studies receive. Orthodox Christians in the USA are not generally advised on what non-MDE foods to consume in greater or lower quantities during their MDE fasting periods.

Concerns have been raised about vegetarian and vegan diets being deficient in vitamin $\mathrm{B}_{12}$, vitamin $\mathrm{D}$, Ca and $\mathrm{Zn}^{(2,83)}$. Such deficiencies may be less of a concern when MDE products are only restricted intermittently by Orthodox Christians. Notably, although the results of the present study demonstrated that strict MDE fasters were consuming less of these nutrients during Lent, low intake was not entirely attributable to the restriction of MDE products. Among strict fasters, average intake of vitamin D and $\mathrm{Ca}$, for example, was also lower than the RDA before Lent, and chronically low intake of vitamin $\mathrm{D}$ and $\mathrm{Ca}$ is common among Greek OC populations as well ${ }^{(51)}$. Vitamin $B_{12}$, on the other hand, surprisingly does not consistently appear to decrease in relation to MDE fasting ${ }^{(51)}$, and the only other OC study to report on Zn intake similarly found no effect of the MDE fast ${ }^{(30)}$. At the same time, MDE fasting was in this and other studies of OC populations associated with an increase in folate, $\mathrm{Mg}$ and $\mathrm{Fe}$, the latter of which may be attributable to increases in shellfish, legumes and nuts ${ }^{(51)}$.

The present study is unique in that it captures the intraindividual change in the dietary and nutritional composition of a free-living population when advised to restrict MDE products but allowed free choice on which foods to consume as MDE replacements. A major strength of the present study is its use of 7-d FR to corroborate the study results obtained from the retrospective FFQ data. Nonetheless, both dietary assessment methods are prone to reporting errors and desirability bias, and the act of tracking one's diet can influence food choices $^{(84-87)}$. Nutritional databases may not offer precise measures of macro- and micronutrient intake for foods that can vary in their composition. The composite measure of MDE reductions used in the present study does not capture the potentially distinct 
nutritional effects of reducing meat $v$. dairy product or eggs (or sub-categories of meat and dairy products). Restricting the study sample to individuals who were born and/or raised in the USA or Canada limits the degree to which the present study's findings can be generalised to the many foreign-born Orthodox Christians living in the USA or Orthodox Christians in other regions of the world. The fact that this sample was relatively well educated, part of a higher socioeconomic stratum, residing in the southern region of the USA, and willing to invest time in tracking their diet for the present study also limits the generalisability of these study findings to other demographics. Moreover, the generalisability of the present study's results to other meat-restricting populations may be limited, given that Orthodox Christians may still consume fish, alter their meal patterns or avoid other 'vices' during Lent. Likewise, the study findings may also not be generalisable to other OC populations that realise the Lenten fasting practice differently or who may have more access to affordable, home-grown fruits and vegetables or less exposure to processed foods ${ }^{(31)}$. Finally, the present study may have lacked the statistical power to detect changes in some plant-based foods as significant due, in part, to small and highly variable degrees of change in some plant-based foods. However, such variability further highlights the lack of uniformity in the composition of MDErestricted diets and demonstrates that the choice to adopt a plant-based diet does not necessarily motivate increased consumption of all healthy, nutritious plant-based foods.

In conclusion, spiritually motivated MDE restrictions among this sample of Orthodox Christians in the USA improved some but not all aspects of their dietary and nutritional composition. Our results suggest that even motivated MDE fasters may not meet all healthy dietary requirements, which may in turn modify any potential health benefits from MDE fasting. Guidance to increase intake of vegetables, fruits and whole grains and reduce consumption of refined grains and added sugars may be important for Orthodox Christians or other individuals who temporarily or permanently choose to restrict MDE products for religious or spiritual purposes. The effect of MDE fasting on dietary composition and health may vary across populations and may depend on baseline dietary habits and the quality of plant-based foods that are accessible and chosen as MDE replacements. Further research is needed to evaluate the factors guiding plant-based food choices and the health-related costs and benefits of these choices during MDE fasts, as practiced by Orthodox Christians in the USA and worldwide.

\section{Acknowledgements}

We would like to acknowledge all of the participants who dedicated so much of their time to completing study tasks and who made the present study possible. We would also like to acknowledge the parish priests and parishioners who helped with participant recruitment and offered space to conduct research-related tasks. Sincere thanks to friends and family who supported this project financially. Thanks to Dr Bettina Shell-Duncan who contributed to the design and framing of the present study.

Partial support for this research came from a National Science Foundation Doctoral Dissertation Research Grant (H. J. B. and K. O., BCS-1540282); a Shanahan Endowment Fellowship and a Eunice Kennedy Shriver National Institute of Child Health and Human Development training grant offered through the Center for Studies in Demography and Ecology at the University of Washington (H. J. B., T32 HD007543); and crowdfunding donations through Experiment.com (H. J. B).

All authors contributed to designing the research; H. J. B. conducted the research and analyzed the data; H. J. B. wrote the first draft of the paper and had the primary responsibility for the final content. All authors read and approved the final manuscript.

H. J. B. and K. O. have no conflicts of interest to disclose. M. K. has received reimbursements for travel, honoraria for speaking, and a research grant from dairy-related organisations, including the Dairy Research Institute/Dairy Management Inc., Dairy Farmers of Canada, Dairy Australia, CNIEL (France) and NZO (The Netherlands). However, no industry funding was received to conduct the work described in this paper.

\section{Supplementary material}

For supplementary material/s referred to in this article, please visit https://doi.org/10.1017/S0007114519001533

\section{References}

1. Craig WJ \& Mangels AR (2009) Position of the American Dietetic Association: vegetarian diets. J Am Diet Assoc 109, 1266-1282.

2. Melina V, Craig W \& Levin S (2016) Position of the academy of nutrition and dietetics: vegetarian diets. J Acad Nutr Diet 116, 1970-1980.

3. Fraser GE (2009) Vegetarian diets: what do we know of their effects on common chronic diseases? Am J Clin Nutr 89, 1607S-1612S.

4. Dyett PA, Sabaté J, Haddad E, et al. (2013) Vegan lifestyle behaviors. An exploration of congruence with health-related beliefs and assessed health indices. Appetite 67, 119-124.

5. Radnitz C, Beezhold B \& DiMatteo J (2015) Investigation of lifestyle choices of individuals following a vegan diet for health and ethical reasons. Appetite 90, 31-36.

6. Orlich MJ, Jaceldo-Siegl K, Sabaté J, et al. (2014) Patterns of food consumption among vegetarians and non-vegetarians. Br J Nutr 112, 1644-1653.

7. Jaacks LM, Kapoor D, Singh K, et al. (2016) Vegetarianism and cardiometabolic disease risk factors: differences between South Asian and US adults. Nutrition 32, 975-984.

8. Rosell M, Appleby P, Spencer E, et al. (2006) Weight gain over 5 years in 21,966 meat-eating, fish-eating, vegetarian, and vegan men and women in EPIC-Oxford. Int J Obes 30, 1389-1396.

9. Singh PN, Arthur KN, Orlich MJ, et al. (2014) Global epidemiology of obesity, vegetarian dietary patterns, and noncommunicable disease in Asian Indians. Am J Clin Nutr 100, 359S-364S.

10. Zhang L, Qin L-Q, Liu A-P, et al. (2010) Prevalence of risk factors for cardiovascular disease and their associations with diet and physical activity in suburban Beijing, China. J Epidemiol 20, 237-243.

11. Rizzo NS, Sabaté J, Jaceldo-Siegl K, et al. (2011) Vegetarian dietary patterns are associated with a lower risk of metabolic syndrome: The Adventist Health Study 2. Diabetes Care 34, 1225-1227.

12. Shang P-H, Shu Z, Wang Y-F, et al. (2011) Veganism does not reduce the risk of the metabolic syndrome in a Taiwanese cohort. Asia Pac J Clin Nutr 20, 404-410.

13. Tonstad S, Butler T, Yan R, et al. (2009) Type of vegetarian diet, vody weight, and prevalence of type 2 diabetes. Diabetes Care 32, 791-796. 
14. Tonstad S, Stewart K, Oda K, et al. (2013) Vegetarian diets and incidence of diabetes in the Adventist Health Study-2. Nutr Metab Cardiovasc Dis 23, 292-299.

15. Berkow SE \& Barnard ND (2005) Blood pressure regulation and vegetarian diets. Nutr Rev 63, 1-8.

16. Appleby PN, Crowe FL, Bradbury KE, et al. (2016) Mortality in vegetarians and comparable nonvegetarians in the United Kingdom. Am J Clin Nutr 103, 218-230.

17. Kwok CS, Mamas MA \& Loke YK (2015) Vegetarian diets and Adventists. Int J Cardiol 190, 383.

18. Kwok CS, Umar S, Myint PK, et al. (2014) Vegetarian diet, Seventh Day Adventists and risk of cardiovascular mortality: a systematic review and meta-analysis. Int J Cardiol 176, 680-686.

19. Mihrshahi S, Ding D, Gale J, et al. (2017) Vegetarian diet and all-cause mortality: evidence from a large population-based Australian cohort - the 45 and Up Study. Prev Med 97, 1-7.

20. Fraser G, Katuli S, Anousheh R, et al. (2015) Vegetarian diets and cardiovascular risk factors in black members of the Adventist Health Study-2. Public Health Nutr 18, 537-545.

21. Grotto D \& Zied E (2010) The standard American diet and its relationship to the health status of Americans. Nutr Clin Pract 25, 603-612.

22. Leitzmann C (2014) Vegetarian nutrition: past, present, future. Am J Clin Nutr 100, 496S-502S.

23. Satija A, Bhupathiraju SN, Rimm EB, et al. (2016) Plant-based dietary patterns and incidence of type 2 diabetes in us men and women: Results from three prospective cohort studies. PLoS Med 13, e1002039.

24. Satija A, Bhupathiraju SN, Spiegelman D, et al. (2017) Healthful and unhealthful plant-based diets and the risk of coronary heart disease in U.S. adults. J Am Coll Cardiol 70, 411-422.

25. Craig WJ (2009) Health effects of vegan diets. Am J Clin Nutr 89, $1627 \mathrm{~S}-1633 \mathrm{~S}$

26. Mozaffarian D (2016) Dietary and policy priorities for cardiovascular disease, diabetes, and obesity: a comprehensive review. Circulation 133, 187-225.

27. Mozaffarian D, Hao T, Rimm EB, et al. (2011) Changes in diet and lifestyle and long-term weight gain in women and men. $N$ Engl J Med 364, 2392-2404.

28. Yang Q, Zhang Z, Gregg EW, et al. (2014) Added sugar intake and cardiovascular diseases mortality among US adults. JAMA Intern Med 174, 516-524.

29. Sarri KO, Linardakis MK, Bervanaki FN, et al. (2004) Greek Orthodox fasting rituals: a hidden characteristic of the Mediterranean diet of Crete. Br J Nutr 92, 277-284.

30. Papadaki A, Vardavas C, Hatzis C, et al. (2008) Calcium, nutrient and food intake of Greek Orthodox Christian monks during a fasting and non-fasting week. Public Health Nutr 11, 1022-1029.

31. Karras SN, Koufakis T, Petróczi A, et al. (2019) Christian Orthodox fasting in practice: a comparative evaluation between Greek Orthodox general population fasters and Athonian monks. Nutrition 59, 69-76.

32. Karras SN, Persynaki A, Petroczi A, et al. (2017) Health benefits and consequences of the Eastern Orthodox fasting in monks of Mount Athos: a cross-sectional study. Eur J Clin Nutr 71, 743-749.

33. Elshorbagy A, Jerneren F, Basta M, et al. (2017) Amino acid changes during transition to a vegan diet supplemented with fish in healthy humans. Eur J Nutr 56, 1953-1962.

34. Patterson RE, Kristal AR, Tinker LF, et al. (1999) Measurement characteristics of the women's health initiative food frequency questionnaire. Ann Epidemiol 9, 178-187.

35. Nutrition Assessment Shared Resources (NASR) of Fred Hutchinson Cancer Research Center (FHCRC) (2015) Food Frequency Questionnaires (FFQ). http://sharedresources.fredhutch.org/ services/food-frequency-questionnaires-ffq
36. Kwan ML, Kushi LH, Song J, et al. (2010) A practical method for collecting food record data in a prospective cohort study of breast cancer survivors. Am J Epidemiol 172, 1315-1323.

37. Kolar AS, Patterson RE, White E, et al. (2005) A practical method for collecting 3-day food records in a large cohort. Epidemiology 16, 579-583.

38. Nutrition Assessment Shared Resources (NASR) of Fred Hutchinson Cancer Research Center (FHCRC) (2015) Multipleday Food Records. https://sharedresources.fredhutch.org/ services/multiple-day-food-records

39. Nutrition Coordinating Center: University of Minnesota (2015) Nutrient Data System for Research. http://www.ncc.umn.edu/ about-ncc/ (accessed March 2017).

40. Bowman SA, Friday JE \& Moshfegh AJ (2008) MyPyramid equivalents database, 2.0 for USDA survey foods, 2003-2004: documentation and user guide. Washington, DC: US Department of Agriculture.

41. Kohl HW, Blair SN, Paffenbarger RS, et al. (1988) A mail survey of physical activity habits as related to measured physical fitness. Am J Epidemiol 127, 1228-1239.

42. Kohl H, Blair S, Paffenbarger R, et al. (1997) The aerobics center longitudinal study physical activity questionnaire. Med Sci Sports Exerc 29, S10-S14.

43. Ainsworth BE, Haskell WL, Herrmann SD, et al. (2011) 2011 compendium of physical activities: a second update of codes and MET values. Med Sci Sports Exerc 43, 1575-1581.

44. US Department of Health Human Services; US Department of Agriculture (2015) 2015-2020 Dietary Guidelines for Americans, 8th ed. Washington, DC: US Department of Agriculture. http://health.gov/dietaryguidelines/2015/guidelines

45. Souza RGM, Gomes AC, Naves MMV, et al. (2015) Nuts and legume seeds for cardiovascular risk reduction: scientific evidence and mechanisms of action. Nutr Rev 73, 335-347.

46. Bazzano LA, Thompson AM, Tees MT, et al. (2011) Non-soy legume consumption lowers cholesterol levels: a meta-analysis of randomized controlled trials. Nutr Metab Cardiovasc Dis 21, 94-103.

47. Sievenpiper JL, Kendall CWC, Esfahani A, et al. (2009) Effect of non-oil-seed pulses on glycaemic control: a systematic review and meta-analysis of randomised controlled experimental trials in people with and without diabetes. Diabetologia 52, 1479.

48. Tindall AM, Johnston EA, Kris-Etherton PM, et al. (2019) The effect of nuts on markers of glycemic control: a systematic review and meta-analysis of randomized controlled trials. Am J Clin Nutr 109, 297-314.

49. Blanco Mejia S, Messina M, Li SS, et al. (2019) A meta-analysis of 46 studies identified by the FDA demonstrates that soy protein decreases circulating LDL and total cholesterol concentrations in adults. J Nutr 149, 968-981.

50. Viguiliouk E, Kendall CWC, Blanco Mejia S, et al. (2014) Effect of tree nuts on glycemic control in diabetes: a systematic review and meta-analysis of randomized controlled dietary trials. PLOS ONE 9, e103376.

51. Koufakis T, Karras S, Antonopoulou V, et al. (2017) Effects of Orthodox religious fasting on human health: a systematic review. Eur J Nutr 56, 2439-2455.

52. Yokoyama Y, Levin SM \& Barnard ND (2017) Association between plant-based diets and plasma lipids: a systematic review and meta-analysis. Nutr Rev 75, 683-698.

53. Wang F, ZhengJ, Yang B, et al. (2015) Effects of vegetarian diets on blood lipids: a systematic review and meta-analysis of randomized controlled trials. J Am Heart Assoc 4, e002408.

54. Yokoyama Y, Barnard ND, Levin SM, et al. (2014) Vegetarian diets and glycemic control in diabetes: a systematic review and meta-analysis. Cardiovasc Diagn Ther 4, 373-382. 
55. Dansinger ML, Gleason J, Griffith JL, et al. (2005) Comparison of the Atkins, Ornish, Weight Watchers, and Zone diets for weight loss and heart disease risk reduction: a randomized trial. JAMA 293, 43-53.

56. Foster GD, Wyatt HR, Hill JO, et al. (2010) Weight and metabolic outcomes after 2 years on a low-carbohydrate versus low-fat diet: a randomized trial. Ann Intern Med 153, 147-157.

57. Gardner CD, Kiazand A, Alhassan S, et al. (2007) Comparison of the Atkins, Zone, Ornish, and Learn diets for change in weight and related risk factors among overweight premenopausal women: The A to L weight loss study: a randomized trial. JAMA 297, 969-977.

58. Lindeberg S, Jönsson T, Granfeldt Y, et al. (2007) A Palaeolithic diet improves glucose tolerance more than a Mediterraneanlike diet in individuals with ischaemic heart disease. Diabetologia 50, 1795-1807.

59. Mellberg C, Sandberg S, Ryberg M, et al. (2014) Long-term effects of a Palaeolithic-type diet in obese postmenopausal women: a two-year randomized trial. Eur J Clin Nutr 68, 350-357.

60. Genoni A, Lyons-Wall P, Lo J, et al. (2016) Cardiovascular, metabolic effects and dietary composition of ad-libitum Paleolithic vs. Australian guide to healthy eating diets: a 4-week randomised trial. Nutrients $\mathbf{8}, 314$.

61. Jönsson T, Granfeldt Y, Ahrén B, et al. (2009) Beneficial effects of a Paleolithic diet on cardiovascular risk factors in type 2 diabetes: a randomized cross-over pilot study. Cardiovasc Diabetol 8, 35.

62. Micha R, Peñalvo JL, Cudhea F, et al. (2017) Association between dietary factors and mortality from heart disease, stroke, and type 2 diabetes in the united states. JAMA 317, 912-924.

63. Aune D, Keum N, Giovannucci E, et al. (2016) Whole grain consumption and risk of cardiovascular disease, cancer, and all cause and cause specific mortality: systematic review and dose-response meta-analysis of prospective studies. BMJ353, i27.

64. Aune D, Norat T, Romundstad P, et al. (2013) Whole grain and refined grain consumption and the risk of type 2 diabetes: a systematic review and dose-response meta-analysis of cohort studies. Eur J Epidemiol 28, 845-858.

65. Hollænder PL, Ross AB \& Kristensen M (2015) Whole-grain and blood lipid changes in apparently healthy adults: a systematic review and meta-analysis of randomized controlled studies. $\mathrm{Am}$ J Clin Nutr 102, 556-572.

66. Leenders M, Boshuizen HC, Ferrari P, et al. (2014) Fruit and vegetable intake and cause-specific mortality in the EPIC study. Eur J Epidemiol 29, 639-652.

67. Gan Y, Tong X, Li L, et al. (2015) Consumption of fruit and vegetable and risk of coronary heart disease: a meta-analysis of prospective cohort studies. Int J Cardiol 183, 129-137.

68. Zhang X, Shu X-O, Xiang Y-B, et al. (2011) Cruciferous vegetable consumption is associated with a reduced risk of total and cardiovascular disease mortality. Am J Clin Nutr 94, 240-246.

69. Bhupathiraju SN, Wedick NM, Pan A, et al. (2013) Quantity and variety in fruit and vegetable intake and risk of coronary heart disease. Am J Clin Nutr 98, 1514-1523.

70. Malik VS, Popkin BM, Bray GA, et al. (2010) Sugar-sweetened beverages and risk of metabolic syndrome and type 2 diabetes: a meta-analysis. Diabetes Care 33, 2477-2483.

71. Stanhope KL, Medici V, Bremer AA, et al. (2015) A dose-response study of consuming high-fructose corn syrup-sweetened beverages on lipid/lipoprotein risk factors for cardiovascular disease in young adults. Am J Clin Nutr 101, 1144-1154.

72. Te Morenga LA, Howatson AJ, Jones RM, et al. (2014) Dietary sugars and cardiometabolic risk: systematic review and meta-analyses of randomized controlled trials of the effects on blood pressure and lipids. Am J Clin Nutr 100, 65-79.

73. Mozaffarian D, Micha R \& Wallace S (2010) Effects on coronary heart disease of increasing polyunsaturated fat in place of saturated fat: a systematic review and meta-analysis of randomized controlled trials. PLoS Med 7, e1000252.

74. Jakobsen MU, O'Reilly EJ, Heitmann BL, et al. (2009) Major types of dietary fat and risk of coronary heart disease: a pooled analysis of 11 cohort studies. Am J Clin Nutr 89, 1425-1432.

75. Li Y, Hruby A, Bernstein AM, et al. (2015) Saturated fats compared with unsaturated fats and sources of carbohydrates in relation to risk of coronary heart disease: a prospective cohort study. J Am Coll Cardiol 66, 1538-1548.

76. Bloomer R, Gunnels T \& Schriefer J (2015) Comparison of a restricted and unrestricted vegan diet plan with a restricted omnivorous diet plan on health-specific measures. Healthcare 3, 544 .

77. Turner-McGrievy GM, Davidson CR, Wingard EE, et al. (2015) Comparative effectiveness of plant-based diets for weight loss: a randomized controlled trial of five different diets. Nutrition 31, 350-358.

78. Mishra S, Xu J, Agarwal U, et al. (2013) A multicenter randomized controlled trial of a plant-based nutrition program to reduce body weight and cardiovascular risk in the corporate setting: the GEICO study. Eur J Clin Nutr 67, 718-724.

79. Barnard ND, Cohen J, Jenkins DJ, et al. (2009) A low-fat vegan diet and a conventional diabetes diet in the treatment of type 2 diabetes: a randomized, controlled, 74-wk clinical trial. $A m \mathrm{~J}$ Clin Nutr 89, 1588S-1596S.

80. Barnard ND, Gloede L, Cohen J, et al. (2009) A low-fat vegan diet elicits greater macronutrient changes, but is comparable in adherence and acceptability, compared with a more conventional diabetes diet among individuals with type 2 diabetes. $J$ Am Diet Assoc 109, 263-272.

81. Turner-McGrievy GM, Barnard ND, Scialli AR, et al. (2004) Effects of a low-fat vegan diet and a Step II diet on macroand micronutrient intakes in overweight postmenopausal women. Nutrition 20, 738-746.

82. Bloomer RJ, Kabir MM, Canale RE, et al. (2010) Effect of a 21 day Daniel Fast on metabolic and cardiovascular disease risk factors in men and women. Lipids Health Dis 9, 94.

83. Craig WJ (2010) Nutrition concerns and health effects of vegetarian diets. Nutr Clin Pract 25, 613-620.

84. Willett W (2013) Nutritional Epidemiology, 3rd ed. Oxford; New York: Oxford University Press.

85. Rebro SM, Patterson RE, Kristal AR, et al. (1998) The effect of keeping food records on eating patterns. J Am Diet Assoc 98, 1163-1165.

86. Goris AH, Westerterp-Plantenga MS \& Westerterp KR (2000) Undereating and underrecording of habitual food intake in obese men: selective underreporting of fat intake. Am J Clin Nutr 71, 130-134.

87. Thompson FE \& Subar AF (2013) Dietary assessment methodology. In Nutrition in the Prevention and Treatment of Disease, 3rd ed. [AM Coulston, C Boushey and MG Ferruzzi, editors]. Oxford; New York: Elsevier/ Academic

88. Office of Dietary Supplements, National Institutes of Health (2019) Nutrient Recommendations: Dietary Reference Intakes (DRI). https://ods.od.nih.gov/Health_Information/Dietary_ Reference_Intakes.aspx (accessed May 2019). 